\title{
Evaluasi Aplikasi Berbasis Power Point Sebagai Sumber Belajar Pada Materi Metode Etnobiologi
}

\section{Salwa Rezeqi ${ }^{(1)}$, Aswarina Nasution ${ }^{(1)}$,Abdul Rasyid Fakhrun Gani( ${ }^{(2)}$,Elviani Br Ginting ${ }^{(1)}$, Emelia Ginting ${ }^{(1)}$}

Program Studi Pendidikan Biologi FMIPA, Universitas Negeri Medan, Medan ${ }^{(1)}$

Program Studi S2 Pendidikan Biologi, FMIPA, Universitas Negeri Malang, Malang ${ }^{(2)}$

$\frac{\text { salwarez@gmail.com (1), aswarinanasution87@gmail.com (2), rasyidabdul547@gmail.com }}{\text { elvianiginting98@gmail.com (4), emelginting@gmail.com (5) }}$

\begin{abstract}
ABSTRAK
Penelitian ini bertujuan untuk mengetahui evaluasi aplikasi berbasis power point sebagai sumber belajar pada materi metode etnobiologi. Penelitian ini termasuk kedalam penelitian deskriptif yang bertujuan untuk mendeskripsikan penerapan penggunaan aplikasi berbasis wtpptconverter pada materi metode penelitian etnobiologi. Populasi pada penelitian ini adalah mahasiswa Jurusan Biologi Universitas Negeri Medan yang mengambil mata kuliah etnobiologi pada tahun 2019/2020 berjumlah 25 mahasiswa. Sampel diambil sebanyak 25 mahasiswa dengan teknik total sampling. Teknik pengumpulan data dilakukan dengan posttest dan wawancara. Hasil pada penelitian ini adalah kelayakan isi aplikasi 80,5\% dalam kategori layak dan kelayakan bahasa $80,8 \%$ dalam kategori layak. Hasil uji postest mahasiswa adalah $77,74 \%$ untuk pengetahuan metode etnobotani, $60,48 \%$ untuk analisis penggunaan metode, dan $74,17 \%$ untuk kepekaan terhadap masalah lingkungan dan solusinya. Berdasarkan hasil wawancara, mahasiswa tertarik menggunakan aplikasi karena memiliki tampilan dan isi yang baik, akan tetapi perlu pengembangan isi konten materi. Dan menurut mahasiswa aplikasi memudahkan mahasiswa dalam menggunakan dan menerapkan metode penelitian etnobiologi dalam kehidupannya sehari-hari. Kesimpulan pada penelitian ini adalah aplikasi sudah baik untuk diterapkan dalam pembelajaran metode penelitian etnobiologi tetapi perlu adanya perbaikan dan pengembangan lebih lanjut.
\end{abstract}

Kata Kunci : Aplikasi, Etnobiologi, Sumber Belajar, Metode Penelitian

\begin{abstract}
This study aims to determine the evaluation of power point-based applications as a learning resource on ethnobiological methods. This research is a descriptive study which aims to describe the application of the use of wtppt converter based applications in ethnobiological research method materials. The population in this study were 25 students of the Department of Biology at the State University of Medan who took ethnobiology courses in 2019/2020. The sample was taken as many as 25 students with a total sampling technique. Data collection techniques were carried out by posttest and interviews. The results of this study are the feasibility of the application content is $80.5 \%$ in the feasible category and the language feasibility of $80.8 \%$ in the feasible category. The results of the students' post-test were $77.74 \%$ for knowledge of the ethnobotany method, $60.48 \%$ for the analysis of method use, and $74.17 \%$ for sensitivity to environmental problems and their solutions. Based on the results of the interview, students are interested in using the application because it has a good appearance and content, but needs to develop the content of the material content. And according to students, the application makes it easier for students to use and apply ethnobiological research methods in their daily lives. The conclusion in this study is that the application is good to be applied in learning ethnobiological research methods but it needs further improvement and development.
\end{abstract}

Keywords : Application, Etnobiology, Learning Resources, Research Method 
Rezeqi S, Nasution Aswarina, Rasyid Fakhrun Gani A, Ginting Elviani, Ginting Emelia : Evaluasi Aplikasi Berbasis Power Point Sebagai Sumber Belajar Pada Materi Metode Etnobiologi

\section{PENDAHULUAN}

\section{Latar Belakang}

Belajar pada umumnya adalah kegiatan untuk memperoleh pengetahuan, keterampilan, dan sikap di mana saja, kapan saja, dan dengan sumber belajar apa saja yang diperoleh (Abdullah, 2012). Sehingga proses belajar dapat dilakukan dimanapun dan kapanpun karena banyaknya sumber belajar yang dapat kita peroleh terutama di era globalisasi sekarang ini. Era globalisasi saat ini merupakan salah satu dampak dari berkembangnya Teknologi Informasi (TI). Perkembangan TI tidak dapat lepas dari teknologi komputer. Hal ini ditunjukkan dengan pesatnya perkembangan perangkat keras (hardware) dan perangkat lunak (software) serta penggunaannya dalam berbagai bidang seperti pendidikan, dunia usaha dan perkantoran dengan menggunakan aplikasi. Salah satu perkembangan teknologi komputer yang paling sering digunakan adalah teknologi jaringan komputer dan internet. Teknologi dapat menyambungkan hampir semua komputer yang ada didunia agar bisa saling berkomunikasi dan bertukar informasi. Informasi yang dapat ditukarkan berupa teks, gambar, video dan suara. Pada zaman sekarang ini, penggunaan teknologi sudah sangat pesat. Teknologi digunakan dalam semua aspek terutama pendidikan salah satu penggunaan teknologi yang marak sekarang ini adalah teknologi sebagai sumber belajar. Komputer dan jaringan komputer yang telah dimanfaatkan dapat memberikan kesempatan kepada setiap pembelajaran untuk mengakses materi ajar yang akan disampaikan kedalam bentuk interaktif melalui jaringan komputer (Munir, 2009). Oleh sebab itu akan sangat mudah bagi seorang guru dalam memanfaatkan komputer dalam menyusun materi sebagai sumber belajar siswa. Sumber belajar adalah rujukan, objek, maupun bahan yang digunakan dalam proses pembelajaran, sedangkan menurut AECT (Assosiation for Educational Communications and Technology) menyatakan sumber belajar adalah segala sesuatu atau daya yang dapat dimanfaatkan oleh guru secara terpisah atau bersama-sama untuk meningkatkan keberhasilan proses belajar mengajar (Mulyasa, 2010). Sumber belajar yang dapat dimanfaatkan untuk kebutuhan pembelajaran sangat beraneka ragam jenis dan bentuknya (Mclsaac \& Gunawardena, 1996). Sumber belajar tersebut bukan hanya dalam bentuk bahan cetakan seperti buku teks akan tetapi pelajar dapat memanfaatkan sumber belajar yang lain seperti radio pendidikan, televisi, komputer, e-mail, video interaktif, komunikasi satelit, dan teknologi komputer multimedia dalam upaya meningkatkan interaksi dan terjadinya umpan balik dengan peserta didik. Etnobiologi merupakan salah satu mata kuliah pilihan di Jurusan Biologi Universitas Negeri Medan. Secara umum etnobiologi dapat diartikan sebagai evaluasi ilmiah tehadap pengetahuan penduduk termasuk masyarakat awam mengenai biologi, termasuk di dalamnya pengetahuan tentang ilmu tumbuhan (botani), ilmu hewan (zoologi) dan ilmu lingkungan alam (ekologi) (Iskandar, 2016). Etnobiologi merupakan disiplin ilmu yang relatif baru yang penting untuk dipelajari. Kajian etnobiologi sendiri bertujuan untuk mencari informasi dan kekayaan intelektual mengenai keanekaragaman hayati dari suatu kearifan lokal (Adinugraha, 2020). Oleh karena itu etnobiologi sangat di disarankan untuk diterapkan di perguruan tinggi negeri guna menumbuhkan kesadaran dan budaya cinta mahasiswa terhadap lingkungan. Guna mendukung pelaksanaan pembelajaran etnobiologi, maka sangat cocok dibuat aplikasi yang dapat mendukung proses pembelajaran yang dapat digunakan oleh mahasiswa sebagai salah satu sumber belajar. Pada penelitian ini, aplikasi etnobiologi yang telah dikembangkan dan dievaluasi merupakan aplikasi yang diubah dari power point dan menggunakan hyperlink hingga dapat digunakan secara interaktif. Power point diubah menjadi aplikasi menggunakan wtppt converter. Aplikasi ini terdiri atas cover, menu utama, dan isi. Isi dibagi atas pretest, materi pembelajaran, mari berfikir, dan postest. Pretest dan postetest berisi pertanyaan 1) pengetahuan metode etnobiologi, 2) analisis pemahaman metode etnobiologi, dan 3) Kepekaan terhadap masalah lingkungan sekitar dan solusinya. Bagian isi terdiri atas 
materi total kegunaan, pebbble distribution method, value use (UVS) dan indeks of cultural significance (ICS). Dan mari berfikir berisi kegiatan untuk menganalisis video dan pemberian pertanyaan-pertanyaan analisis dengan menggunakan metode etnobiologi. Berdasarkan latar belakang tersebut dalam mengembangkan sebuah sumber belajar pada mata kuliah etnobiologi diperlukan tahapan evaluasi. Tahapan evaluasi sangat penting dilakukan karena dapat menentukan efektifitas suatu program, sehingga dapat dilakukan perbaikan atau revisi setelah evaluasi (Plomp \& Nieveen, 2013). Sehingga penelitian ini dilakukan untuk mengevaluasi aplikasi metode penelitian etnobiologi berbasias powerpoint dan dapat digunakan sebagai acuan untuk mengembangkan sumber belajar berbasis teknologi

\section{Perumusan Masalah}

1. Bagaimana hasil penilaian ahli etnobiologi terhadap penggunaan aplikasi metode penelitian etnobiologi berbasis powerpoint?

2. Bagaimana hasil posttest mahasiswa dari pembelajaran dengan menggunakan aplikasi metode penelitian etnobiologi berbasis powerpoint?

3. Bagaimana respon mahasiswa terhadap penggunaan aplikasi metode penelitian etnobiologi berbasis powerpoint?

\section{Tujuan Penelitian}

Penelitian ini bertujuan yaitu :

1. Untuk mengetahui hasil penilaian ahli etnobiologi terhadap penggunaan aplikasi metode penelitian etnobiologi berbasis powerpoint.

2. Untuk mengetahui hasil posttest mahasiswa dari pembelajaran dengan menggunakan aplikasi metode penelitian etnobiologi berbasis powerpoint.

3. Untuk mengetahui respon mahasiswa terhadap penggunaan aplikasi metode penelitian etnobiologi berbasis powerpoint.

\section{Manfaat Penelitian}

1. Untuk mengevaluasi aplikasi metode penelitian etnobiologi agar menjadi lebih baik.

2. Sebagai landasan untuk mengembangkan sumber belajar berbasis teknologi informasi.

3. Sebagai landasan untuk merancang pembelajaran etnobiologi yang lebih baik lagi.

\section{METODE PENELITIAN}

\section{Tempat dan Waktu}

Penelitian ini dilakukan di Universitas Negeri Medan pada bulan Maret-Juni 2019. Populasi pada penelitian ini adalah mahasiswa Jurusan Biologi Universitas Negeri Medan yang mengambil mata kuliah etnobiologi pada tahun 2019/2020 berjumlah 25 mahasiswa. Sampel diambil sebanyak 25 mahasiswa dengan teknik total sampling.

\section{Rancangan Penelitian atau Model}

Penelitian ini termasuk kedalam penelitian deskriptif yang bertujuan untuk mendeskripsikan penerapan penggunaan aplikasi berbasis wtpptconverter pada materi metode penelitian etnobiologi. Evaluasi dilakukan secara kualitatif dengan analisis deskriptif. Menganalisis dengan deskriptif kualitatif dilakukan dengan memberikan predikat kepada variabel dan objek yang diteliti sesuai dengan kondisi sebenarnya (Arikunto, 2013). Dan penelitian ini dilakukan dengan menganalisis dan mendeskripsikan penggunaan aplikasi metode penelitian etnobiologi dari hasil penilaian, posttest, dan wawancara. 
Rezeqi S, Nasution Aswarina, Rasyid Fakhrun Gani A, Ginting Elviani, Ginting Emelia : Evaluasi Aplikasi Berbasis Power Point Sebagai Sumber Belajar Pada Materi Metode Etnobiologi

\section{Tahapan Penelitian}

Penelitian dilakukan dengan tiga tahapan, yaitu tahap persiapan, pengambilan data dan penarikan kesimpulan. Tahap persiapan dilakukan dengan mempersiapkan media, perangkat pembelajaran dan instrument. Instrument pada penelitian ini berupa tes dan lembar wawancara. Pengambilan data dilakukan dengan melakukan penilaian dosen, posttest dan wawancara setelah penggunaan aplikasi ini oleh mahasiswa. Sebelum diterapkan, dilakukan validitas oleh ahli etnobotani lalu aplikasi diberikan kepada mahasiswa sebagai sumber belajarnya. Setelah itu mahasiswa diuji dengan tiga pertanyaan yang mencakup 1) pengetahuan metode etnobiologi, 2) analisis pemahaman metode etnobiologi, dan 3) Kepekaan terhadap masalah lingkungan sekitar dan solusinya. Sedangkan wawancara dilakukan untuk mengetahui tanggapan, respon dan refleksi dari mahasiswa. Data hasil penelitian dianalisis secara deskriptif dengan persentasi maupun narasi.

\section{HASIL DAN PEMBAHASAN}

\section{Penilaian Media oleh Ahli Etnobiologi}

Penilaian oleh dosen ahli pembelajaran etnobiologi setelah dilakukan perbaikan sebanyak dua kali. Adapun hasil validasi materi aplikasi oleh ahli etnobiologi adalah sebagai berikut.

Tabel 1. Hasil validasi ahli etnobiologi

\begin{tabular}{|l|l|l|l|}
\hline No & Bidang telaah & Nilai & Kriteria \\
\hline 1 & Kelayakan Isi Aplikasi & $80,5 \%$ & Layak \\
\hline 2 & Kelayakan Bahasa & $80,8 \%$ & Layak \\
\hline
\end{tabular}

Berdasarkan validasi dan penilaian oleh ahli etnobiologi aplikasi ini sudah memiliki isi yang layak dengan kelengkapan materi ajar yang baik, keluasan materi yang sangat baik, kedalaman materi yang baik, keakuratan konsep dan data yang baik, keakuratan istilah etnobotani yang sangat baik, keakuratan sumber yang sangat baik, keakuratan materi yang baik, tetapi hanya cukup sesuai terhadap tujuan pembelajarannya. Serta pembelajaran dalam aplikasi dirancang berpusat pada mahasiswa, hal ini dapat melibatkan mahasiswa langsung dalam pemanfaatan materi dalam kehidupan sehari hari (Aiman \& Ahmad, 2020). Penggunaan bahasa pada aplikasi ini juga tergolong layak dengan ketepatan struktur kalimat yang baik, ketepatan istilah yang sangat baik, keefektifan kalimat yang baik dan kelaziman istilah yang sangat baik. Penggunaan bahasa yang layak digunakan dalam mengembangkan sumber belajar adalah tata bahasa yang valid, praktis dan efektif (Fauziah et al., 2020). Dan bahasa yang valid perlu digunakan karena media dan sumber belajar merupakan alat yang digunakan untuk mengefektifkan komunikasi dan interaksi antara pendidik dan peserta didik (Marsa \& Desnita, 2020). Sebuah sumber belajar dapat dikatakan valid apabila hasilnya sesuai dengan kriteria, yang artinya hasil tes memiliki kesejajaran dengan kriteria yang telah ditentukan sebelumnya. Untuk uji kevalidan yaitu dengan melihat nilai rata-rata skor semua validator, selanjutnya dilakukan pengkategorian kevalidan (Arikunto, 2013). Dan sebuah data akan valid apabila terdapat kesamaan antara data yang terkumpul dan data yang sebenarnya terjadi. Sehingga aplikasi ini sudah dikategorikan untuk layak digunakan. Berdasarkan analisis data tersebut, kevalidan aplikasi masuk kedalam kategori valid (Sugiyono, 2018). Namun aplikasi ini memiliki kekurangan seperti cakupan yang dibahas mengenai etnobiologi sehingga diperlukan perbaikan untuk penyempurnaan agar aplikasi ini menjadi lebih fleksibel menyesuaikan dengan kebutuhan mahasiswa di perguruan tinggi.

\section{Hasil Postest Mahasiswa}

Adapun hasil posttest yang dilakukan mahasiswa setelah menggunakan aplikasi metode penelitian etnobiologi adalah sebagai berikut. 
Rezeqi S, Nasution Aswarina, Rasyid Fakhrun Gani A, Ginting Elviani, Ginting Emelia : Evaluasi Aplikasi Berbasis Power Point Sebagai Sumber Belajar Pada Materi Metode Etnobiologi

Tabel 2. Hasil postest mahasiswa setelah menggunakan aplikasi

\begin{tabular}{|l|l|l|l|}
\hline No & Jenis Soal & $\begin{array}{l}\text { Persentase } \\
\text { nilai }\end{array}$ & Kriteria \\
\hline 1 & Pengetahuan Metode & $77,74 \%$ & Baik \\
\hline 2 & Analisis Penggunaan Metode & $60,48 \%$ & Cukup \\
\hline 3 & $\begin{array}{l}\text { Kepekaan Terhadap Masalah Lingkungan } \\
\text { Dan Solusinya }\end{array}$ & $74,17 \%$ & Baik \\
\hline & Rata-rata & $70,79 \%$ & Baik \\
\hline
\end{tabular}

Mahasiswa sudah mampu menjelaskan teknik apa saja yang digunakan untuk mengambil data dalam etnobiologi, dengan $77,74 \%$ mahasiswa yang mampu menjawab metode dan langkah-langkah dalam menyelesaikannya seperti penggunaan metode dan cara mengolah datanya. Pada analisis pemahaman metode mahasiswa hanya bisa menjawab dengan tepat tetapi beberapa mahasiswa belum memberikan alasan yang spesifik dalam menjabarkan hasil analisisnya. Pada kepekaan terhadap masalah lingkungan dan solusinya, mahasiswa sudah berhasil menemukan masalah yang ada dalam lingkungannya sehari-hari dan dapat memberikan ide untuk mengatasinya tetapi beberapa mahasiswa belum menerapkan tahapan metode etnobiologi dalam menyelesaikan masalah tersebut. Berdasarkan hasil postest tersebut, hasil belajar kognitif mahasiswa sudah dikategorikan baik (Arikunto, 2013). Dalam hal ini artinya penggunaan aplikasi etnobiologi sudah berlangung dengan baik. Belajar menggunakan aplikasi dapat meningkatkan hasil belajar dan respon positif siswa. Hal ini terjadi karena penggunaan sumber belajar berbasis digital dapat mengoptimalkan pembelajaran yang dilaksanakan (Sanjayanti et al., 2020). Dan pembelajaran menggunakan teknologi disesuaikan dengan tuntutan pembelajaran di abad ke-21 (Zubaidah, 2016). Akan tetapi diperlukan beberapa perbaikan untuk meningkatkan hasil belajar etnobiologi mahasiswa. Hal yang perlu diperbaiki dapat berupa kedalaman materi, penambahan gambar dan video yang dapat menambah wawasan dan pengalaman mahasiswa. Hal yang perlu dilakukan untuk menambah pengetahuan peserta didik adalah dengan memberikan gambar literatur yang baik (S. Rezeqi \& Handayani, 2018). Gambar literatur dan materi tersebut akan lebih efektif jika disajikan beberapa warna, hal ini terjadi karena penggunaan warna salah satu cara dalam menyajikan informasi yang bertujuan untuk memudahkan ketercapaian tujuan belajar (Anam, 2015). Untuk meningkatkan pengetahuan mahasiswa terhadap metode penelitian etnobiologi maka diperlukan juga perbaikan desain dan daya tarik aplikasi. Desain harus di sesuaikan pada karakteristik materi etnobiologi dan dibuat dengan versi yang lebih menarik untuk menarik minat mahasiswa. Dan keberhasilan seseorang sangat besar dipengaruhi oleh faktor minat karena bersumber langsung dari dalam diri seseorang sehingga keuletan yang dimiliki akan membentuk karakteristik ataupun kebiasaan seseorang tersebut dalam belajar (Salwa Rezeqi et al., 2020).

\section{Hasil Wawancara Mahasiswa}

Berdasarkan hasil wawancara, rata-rata mahasiswa menyatakan bahwa materi metode penelitian etnobiologi sudah luas dan sesuai dengan pembelajaran, tetapi ada yang berpendapat bahwa perlu adanya ditambah detail untuk lebih memahamkan mahasiswa dalam penggunaan metode etnobiologi. Mahasiswa juga berpendapat bahwa soal posttest yang dilakukannya sudah baik, karena dapat menuntut mahasiswa berfikir dan menganalisis penggunaan aplikasi etnobiologi yang dipelajari. Aplikasi ini juga menyajikan video permasalahan yang nyata dan dialami langung oleh mahasiswa, seperti video tergerusnya pewarna alami dalam pembuatan ulos. Hal ini dapat memudahkan mahasiswa dalam menggunakan dan menerapkan metode penelitian etnobiologi dalam kehidupannya sehari- 
hari. Pengembangan sumber belajar yang baik harus terintegrasi dengan realitas yang diketahui oleh peserta didik. Dengan demikian pengembangan sumber belajar berbasis peserta didik menjadi salah satu cara pengembangan yang terintegrasi dan efektif untuk dilakukan (Jailani, 2016). Menurut mahasiswa aplikasi ini dapat menambah minat belajar peserta didik karena desainnya yang cukup menarik. Desain yang telah disusun termasuk ke dalam desain sederhana yang hanya memadukan warna warna ringan seperti biru muda, jingga, dan merah muda sehingga tidak mengganggu pengelihatan saat membacanya. Aplikasi juga di desain tidak memiliki banyak tulisan, hanya terdiri dari kalimat utama, sedikit penjelasan dan rumus-rumus terkait metode penelitian etnobiologi. Sumber belajar yang dapat menarik minat belajar peserta didik dapat membantu peserta didik dalam mencapai tujuan pembelajaran di dalam kelas (Suryani \& Ayu, 2018). Karakteristik peserta didik yang mempunyai minat yang kuat dalam belajar dapat dikenali dari perhatian, kemauan dan konsentrasi peserta didik. Minat sendiri erat kaitannya dengan perasaan, terutama perasaan senang (Larlen, 2012). Aplikasi ini juga dapat digunakan secara berkelompok yang bisa meningkatkan minat dan keterampilan berkolaborasi untuk bekerja bersama secara efektif dalam pembelajaran (Sanjayanti et al., 2020). Oleh karena itu minat memiliki pengaruh yang besar terhadap capaian pembelajaran. Maka dari itu dapat disimpulkan bahwa minat belajar peserta didik dapat berperan sebagai pendorong bagi peserta didik untuk memperoleh hasil yang baik. Penelitian sebelumnya menyatakan bahwa media pembelajaran power point memberikan peningkatan minat peserta didik dalam beberapa kali uji coba disetiap pertemuannya, sehingga media power point efektif digunakan di kelas (Khaerunnisa, 2018). Apalagi aplikasi ini dapat diunduh dan diinstall melalui situs yang disediakan oleh dosen bertujuan untuk memudahkan mahasiswa dalam menggunakannya dan sesuai perkembangan zaman, dan sumber informasi yang biasa digunakan mahasiswa adalah yang berbasis internet dan online (Gani et al., 2020; Gani \& Arwita, 2020). Sehingga aplikasi ini praktis untuk diterapkan di dalam kelas dan diluar kelas sebagai sumber belajar dan sumber informasi.

\section{KESIMPULAN}

Kesimpulan pada penelitian ini adalah kelayakan isi aplikasi $80,5 \%$ dalam kategori layak dan kelayakan bahasa $80,8 \%$ dalam kategori layak. Hasil uji postest mahasiswa adalah $77,74 \%$ untuk pengetahuan metode etnobotani, 60,48\% untuk analisis penggunaan metode, dan $74,17 \%$ untuk kepekaan terhadap masalah lingkungan dan solusinya. Berdasarkan hasil wawancara, mahasiswa tertarik menggunakan aplikasi karena memiliki tampilan dan isi yang baik, akan tetapi perlu pengembangan isi konten materi.

\section{DAFTAR PUSTAKA}

Abdullah, R. (2012). Pembelajaran Berbasis Pemanfaatan Sumber Belajar. Jurnal Ilmiah DIDAKTIKA, 12(2).

Adinugraha, F. (2020). Potensi Reresik Sumur Pitu Sebagai Pendekatan Kearifan Lokal dan Budaya pada Pembelajaran Biologi. Jurnal Pendidikan Surya Edukasi (JPSE), 6(1), 16-32. https://doi.org/10.37729/jpse.v6i1.6490

Aiman, U., \& Ahmad, R. A. R. (2020). Model Pembelajaran Berbasis Masalah (PBL) terhadap literasi sains siswa kelas V Sekolah Dasar. Jurnal Pendidikan Dasar Flobamorata, 1(1), 1-5.

Anam, K. (2015). Pengaruh Media Pembelajaran Terhadap Minat Belajar Siswa Pada Mata Pelajaran PAI Di SMP Bani Muqiman Bangkalan. Jurnal Pendidikan Islam, 4(1).

Arikunto, S. (2013). Manajemen Penelitian. Rineka.

Fauziah, M., Sulaeman, Y., \& Chandra, C. (2020). Pengembangan Lks Tematik Bahasa Indonesia Kelas V Melalui Kegiatan Lesson Study Di Sekolah Dasar. Jurnal 
Rezeqi S, Nasution Aswarina, Rasyid Fakhrun Gani A, Ginting Elviani, Ginting Emelia : Evaluasi Aplikasi Berbasis Power Point Sebagai Sumber Belajar Pada Materi Metode Etnobiologi

Cakrawala Pendas, 6(1), 15-22. https://doi.org/10.31949/jcp.v6i1.1559

Gani, A. R. F., \& Arwita, W. (2020). Kecenderungan Literasi Informasi Mahasiswa Baru Pada Mata Kuliah Morfologi Tumbuhan. Jurnal Pelita Pendidikan, 8(2), 145-150. https://jurnal.unimed.ac.id/2012/index.php/pelita/index

Gani, A. R. F., Arwita, W., Syahraini, S., \& Daulay, N. K. (2020). Literasi Informasi Dalam Tugas Mini Riset Mahasiswa Baru Jurusan Biologi Pada Mata Kuliah Morfologi Tumbuhan. Jurnal Pelita Pendidikan, 8(3), 174-180.

Iskandar, J. (2016). Etnobiologi dan Keragaman Budaya di Indonesia. UMBARA: Indonesian Journal of Anthropology, 1(1).

Jailani, M. S. (2016). Pengembangan Sumber Belajar Berbasis Karakter Peserta Didik (Ikhtiar optimalisasi Proses Pembelajaran Pendidikan Agama Islam (PAI)). Jurnal Pendidikan Islam, 10(2).

Khaerunnisa, F. (2018). Pengaruh Penggunaan Media Power Point Terhadap Minat Belajar Sejarah Siswa Kelas X SMA Negeri 1 Bumiayu Tahun Ajaran 2017/2018. Indonesian Journal of History Education, 6(1).

Larlen. (2012). Upaya Meningkatkan Minat Belajar Bahasa Indonesia Melalui Pemanfaatan Teknologi Pada Pembelajaran Kelas X SMA Pelita Raya Jambi. Jurnal Pena, 2(2).

Marsa, P. B., \& Desnita, D. (2020). Analisis Media, Sumber Belajar, dan Bahan Ajar Yang Digunakan Guru Fisika SMA Materi Gelombang Di Sumatera Barat Ditinjau Dari Kebutuhan Belajar Abad 21. Jurnal Eksakta Pendidikan (Jep), 4(1), 81. https://doi.org/10.24036/jep/vol4-iss1/422

Mclsaac, M. S., \& Gunawardena. (1996). Handbook of Research for Educational Communications and Technology. AECT.

Mulyasa. (2010). Kurikulum Tingkat Satuan Pendidikan. PT Remaja Rosdakarya.

Munir. (2009). Pembelajaran Jarak Jauh Berbasis Teknologi Informasi dan Komunikasi. Alfabeta.

Plomp, T., \& Nieveen, N. (2013). Educational Desain Research. Enschede.

Rezeqi, S., \& Handayani, D. (2018). Pengembangan Media Pembelajaran Pterydopyta Berbasis Herbaruim. Jurnal Pelita Pendidikan, 6(1), 38-41.

Rezeqi, Salwa, Brata, W. W. W., Handayani, D., \& Gani, A. R. F. (2020). Analisis Kebutuhan Bahan Ajar Taksonomi Organisme Tingkat Rendah Terhadap Capaian Pembelajaran Berbasis KKNI. Jurnal Pelita Pendidikan, 7(2), 080-086.

Sanjayanti, N. P. A. H., Darmayanti, N. W. S., Qondias, D., \& Sanjaya, K. O. (2020). Integrasi Keterampilan 4C Dalam Modul Metodologi Penelitian. Jurnal Pedagogi dan Pembelajaran, 3(3), 407-415.

Sugiyono. (2018). Metode Penelitian Pendidikan (Pendekatan Kuantitatif, Kualitatif, dan $R \& D)$. Alfabeta.

Suryani, E., \& Ayu, W. (2018). Pengaruh Sumber Belajar Terhadap Minat Belajar Bahasa Arab Siswa Kelas VII MTs Negeri 2 Sumbawa Kabupaten Sumbawa Besar. Jurnal UIN Mataram, 17(1).

Zubaidah, S. (2016). Keterampilan Abad Ke-21: Keterampilan Yang Diajarkan Melalui Pembelajaran. Jurnal Penelitian Pendidikan, June, 1-17.

\begin{tabular}{|l|l|l|l|}
\hline Accepted Date & Revised Date & Decided Date & Accepted to Publish \\
\hline 05 Desember 2020 & 08 Desember 2020 & 15 Desember 2020 & Ya \\
\hline
\end{tabular}

